\title{
Reduction of direct costs in high-risk lumbar discectomy patients during the 90-day post-operative period through annular closure
}

This article was published in the following Dove Medical Press journal: ClinicoEconomics and Outcomes Research

\author{
Bart Thaci' \\ Matthew J McGirt ${ }^{2}$ \\ Joshua M Ammerman ${ }^{3}$ \\ Claudius Thomé ${ }^{4}$ \\ Kee D Kim' \\ Jared D Ament ${ }^{5}$ \\ 'Department of Neurological Surgery, \\ University of California, Davis, \\ Sacramento, CA, USA; ${ }^{2}$ Department \\ of Neurological Surgery, Carolina \\ Neurosurgery and Spine Associates, \\ Charlotte, NC, USA; ${ }^{3}$ Department \\ of Surgery, Sibley Memorial Hospital, \\ Washington DC, USA; ${ }^{4}$ Deparment \\ of Neurosurgery, Innsbruck Medical \\ University, Innsbruck, Austria; ${ }^{5}$ Sierra \\ Neuroscience Institute, Los Angeles, \\ CA, USA
}

Purpose: Despite being an extremely successful procedure, recurrent disc herniation is one of the most common post-discectomy complications in the lumbar spine and contributes significant health care and socioeconomic costs. Patients with large annular defects are at a high risk for reherniation, but an annular closure device (ACD) has been designed to reduce reherniation risk in this population and may, in turn, help control direct health care costs after discectomy. Patients and methods: This analysis examined the 90-day post-discectomy cost estimates among ACD-treated ( $\mathrm{n}=272$ ) and control (discectomy alone; $\mathrm{n}=278$ ) patients in a randomized controlled trial (RCT). Direct medical costs were estimated based on 2017 Humana and Medicare claims. Index discectomies were assumed to occur in an outpatient (OP) setting, whereas repeat discectomies were assumed to be $60 \%$ in OP and $40 \%$ in inpatient (IP). A sensitivity analysis was performed on this assumption. The device cost was not included in the analysis in order to focus on costs in the 90-day post-operative period.

Results: Within 90 days of follow-up, post-operative complications occurred in $3.3 \%$ of the ACD patients and $8.6 \%$ of the control patients $(P=0.01)$. The average 90 -day cost to treat an ACD patient was $\$ 10,257$ compared to $\$ 11,299$ per control patient for a 80:20 distribution of Commercial:Medicare coverage ( $\$ 1,042$ difference). This difference varied from $\$ 687$ with $100 \%$ Medicare to $\$ 1,132$ with $100 \%$ Commercial coverage. Varying the IP vs OP distribution resulted in a cost difference range of $\$ 968$ to $\$ 1,156$ with the ACD.

Conclusion: Augmenting discectomy with an ACD in high-risk patients with a large annular defect reduced reherniation and reoperation rates, which translated to a reduction of direct health care costs between $\$ 687$ and $\$ 1,156$ per patient during the 90 -day post-operative period. Large annular defect patients are an easily identifiable high-risk population. Operative strategies that reduce complication risks in these patients, such as the ACD, could be advantageous from both patient care and economic perspectives.

Keywords: annular closure device, value-based care, 90-day bundle, lumbar discectomy, large annular defect, recurrent herniation

\section{Introduction}

Treatment of spine-related conditions in USA accounts for over $\$ 86$ billion in health care costs per year. ${ }^{1}$ The current "fee-for-service" model lacks the necessary incentives to curb follow-up costs since reimbursement is not often directly linked to quality of care. ${ }^{2}$ Under the traditional fee-for-service arrangement, primary and revision procedures are reimbursed independently. As a result, institutions may not be financially incentivized to minimize secondary procedures. Bundled payment strategies, which
Sierra Neuroscience Institute, 1701 E

Cesar E Chavez Ave, Suite 356, Los

Angeles, CA 90033, USA

$\mathrm{Tel}+\mathrm{I} 3233523000$

Fax +I 3233523016

Email jaredament@gmail.com 
provide reimbursement based on the entire episode of care, are an example of one strategy that has been designed with the intent to mitigate expenditures. ${ }^{2}$ The goal is to incentivize practitioners and institutions to make evidence-based decisions that curtail acute costs including extended hospital stay, associated adverse events, rehospitalization and repeat surgery, without sacrificing patient safety. In an effort to move toward a bundled-payment system, reimbursements have been sequestered to specific "episodes of care". Based on the Centers for Medicare and Medicaid Services (CMS) rules, some payers have adopted a 90-day post-operative period for specific types of surgeries. ${ }^{3}$

The costs of inpatient (IP), non-instrumented spinal surgery currently range from $\$ 13,924$ to $\$ 21,638$, depending on the complexity and associated complications. ${ }^{4}$ Quoted costs here include the surgery, surgeon fee, hospital stay, and post-discharge care. In an effort to control these costs, many procedures, such as lumbar discectomy, are being performed more commonly in the outpatient (OP) setting. ${ }^{5}$ Yet, one report suggested that transitioning to OP discectomy may be associated with increased readmission rates, which would reduce much of any initial savings that may have been realized in this lower cost setting of care. ${ }^{5}$

The most common cause for reoperation following lumbar discectomy is recurrent herniation, constituting about $70 \%$ of the reoperations. ${ }^{6,7}$ A previous analysis of 90 -day episode-of-care reimbursements observed that post-acute care (eg, injections, skilled nursing, and revision surgery) accounted for up to $16 \%$ of the costs related to discectomy or decompression procedures in a population that experienced reoperation rates around $2 \%-3 \%{ }^{8}$ However, patients with large annular defects ( $\geq 6 \mathrm{~mm}$ width) are 2.3 times more likely to require reoperation for recurrent herniation than patients with smaller annular defects. ${ }^{9}$ Therefore, this large annular defect population would incur significantly greater post-acute care costs.

To address the unmet medical need of preventing recurrent lumbar disc herniation in patients with large annular defects, substantial development efforts have focused on closure of the annular defect through occlusion or repair devices. Several recent studies have demonstrated that an annular closure device (ACD) can reduce recurrent herniation rates in this high-risk population by $50 \% .^{10-13}$ The purpose of this study was to compare 90-day post-operative costs in patients with large annular defects receiving the ACD vs control (standard lumbar discectomy). We hypothesized that costs during the 90-day post-operative period would be lower among patients who received the ACD than those receiving discectomy alone, independent of the device cost.

\section{Patients and methods Participants}

This is a post hoc analysis of an international, randomized, multicenter, trial involving patients with radicular leg pain due to lumbar disc herniation. ${ }^{11,14}$ The randomized controlled trial (RCT) was approved by all ethics review boards (Supplementary materials) and prospectively registered with ClinicalTrials.gov (NCT01283438). All patients provided written informed consent, and the study was conducted in compliance with the Declaration of Helsinki. Patients were eligible for inclusion if they presented with image-confirmed, single-level disc herniation between L2 and S1, with a posterior disc height of $\geq 5 \mathrm{~mm}$ and unresponsiveness to at least 6 weeks of conservative care. A principal inclusion criterion was the presence of a large annular defect after discectomy, defined as $\geq 6 \mathrm{~mm}$ width. Patients were excluded if they had the following: previous lumbar spine surgery, foraminal or extraforaminal disc herniation, extraspinal cause of sciatica, pre-existing spinal pathology, bone mineral density with a $t$-score of less than -2.0 (for subjects requiring DEXA), scoliosis of $>10^{\circ}$, or other abnormalities such as spondylolysis or spondylolisthesis.

\section{Randomization}

Patients were randomized intraoperatively following discectomy using a web-based computer-generated random treatment assignment. Patients were randomized in a 1:1 ratio to receive either discectomy with the ACD or discectomy alone. All patients provided informed consent for inclusion in the study prior to their surgery. A total of 554 patients were randomized as follows: 276 patients to the ACD group and 278 patients to the control group. Details on the use of the ACD and surgical procedure have been described previously. ${ }^{10-13}$

\section{Clinical outcomes}

Complications were based on serious adverse events (SAEs), which were defined in the RCT according to the guidelines of the International Organization for Standardization (ISO) document 14155:2011. ${ }^{15}$ Complications that were analyzed included recurrent herniation, wound dehiscence, infection, epidural hematoma, and device-related complications. Recurrent herniations were confirmed intraoperatively at the time of reoperation or by recurrence of neurological symptoms and magnetic resonance imaging (MRI) findings. 


\section{Direct procedure-related costs}

Direct medical costs that were included in the analysis were associated with operating room time, facility/hospital stay, post-operative medications, physical therapy, epidural steroid or facet injections, reoperations for symptomatic reherniations, diagnostic imaging, follow-up visits (scheduled and unscheduled), and surgery-related complications. The estimated costs associated with these events were based on 2017 Humana and Medicare claims data that were derived from a commercially available payer database (PearlDiver) to represent nationwide private and public payer data, respectively. Payer reimbursements were abstracted for pertinent diagnosis-related groups (DRG) for IP scenarios, Ambulatory Payment Classifications (APC) for OP scenarios, and Current Procedural Terminology (CPT) codes for relevant procedures and services (Table 1). Ancillary costs associated with complications or revisions, including follow-up office visits, epidural steroid injections (ESI), spine imaging (computed tomography/MRI), and physical therapy, were classified together as "conservative therapy total" (Table 1).

The calculations for medication costs were based on the average wholesale price (AWP) from the 2011 Redbook MarketScan. ${ }^{16}$ The cost was estimated using AWP times $85 \%$, based on Medicare's 2010 reimbursement rate for medications. To understand the cost-benefit over time for patients receiving the ACD compared to conventional discectomy within the US healthcare system, the following assumptions were made: all index operations occurred in the OP setting and repeat discectomies were performed on a $60 \%$ OP and $40 \%$ IP basis. ${ }^{17}$ Costs were modeled under varying distributions of insurance coverage, including 100:0, 80:20, 50:50, 20:80, and 0:100 proportions for Commercial:Medicare. A sensitivity analysis was also performed to evaluate the effect of repeat discectomies being performed in an OP vs IP setting. The cost of the ACD was not included in this analysis in order to focus on comparisons of post-operative care and to determine potential pricing thresholds. All cost inputs were adjusted for inflation to 2017 US dollars by using the US medical care Consumer Price Index (CPI). ${ }^{18}$

\section{Statistics}

Descriptive statistics were calculated and recorded as mean and SD. Comparisons between groups were made using chisquare or Fisher's exact tests. Statistical significance was set a priori at $P<0.05$.

\section{Results}

The 90-day clinical outcomes of this RCT have been previously described. ${ }^{11}$ Within 90 days of follow-up, post-operative
Table I Estimated costs for each intervention by payer type

\begin{tabular}{|c|c|c|}
\hline & $\begin{array}{l}\text { Medicare } \\
\text { (\$USD) }\end{array}$ & $\begin{array}{l}\text { Commercial } \\
\text { (\$USD) }\end{array}$ \\
\hline \multicolumn{3}{|l|}{ Index operation (outpatient) } \\
\hline Medicare $-\mathrm{PT} \times 2$ sessions & 122.85 & 93.04 \\
\hline Medicare - MRI & 203.84 & 791.94 \\
\hline Medicare - CT & 146.26 & 140.33 \\
\hline Medicare - injection $\times 2$ & 132.34 & 290.66 \\
\hline APC 5 II4 (Medicare) & $5,219.36$ & $7,150.52$ \\
\hline Medicare - surgeon & 578.63 & $1,938.61$ \\
\hline Total & $6,403.28$ & $10,405.10$ \\
\hline \multicolumn{3}{|l|}{ Recurrence discectomy } \\
\hline \multicolumn{3}{|l|}{ (outpatient) } \\
\hline Medicare - conservative therapy & 892.49 & $1,621.35$ \\
\hline APC 5 I I4 (Medicare) & $5,219.36$ & $7,150.52$ \\
\hline Medicare - surgeon & 578.63 & $1,938.61$ \\
\hline Total & $6,596.24$ & $10,710.48$ \\
\hline \multicolumn{3}{|l|}{ Recurrence discectomy } \\
\hline Medicare - conservative therapy & 892.49 & $1,621.35$ \\
\hline Medicare - DRG 519 & $10,290.00$ & $15,526.14$ \\
\hline Medicare - surgeon & 578.63 & I,938.6I \\
\hline Total & $11,666.88$ & $19,086.10$ \\
\hline \multicolumn{3}{|l|}{ Recurrence with fusion } \\
\hline Medicare - conservative therapy & 892.49 & $1,621.35$ \\
\hline Medicare DRG 459/460 & $30,945.65$ & $49,760.12$ \\
\hline Medicare - surgeon & 619.60 & $2,034.79$ \\
\hline Total & $32,363.50$ & $53,416.26$ \\
\hline \multicolumn{3}{|l|}{ Epidural hematoma } \\
\hline Medicare - conservative therapy & 892.49 & $1,621.35$ \\
\hline Medicare - DRG 920 & $6,327.00$ & $7,402.00$ \\
\hline Medicare - surgeon & 424.06 & $1,279.62$ \\
\hline Total & $7,549.31$ & $10,302.97$ \\
\hline \multicolumn{3}{|l|}{ Wound infection } \\
\hline Medicare - conservative therapy & 892.49 & $1,621.35$ \\
\hline Medicare - DRG 856 & $16,948.88$ & $24,177.83$ \\
\hline Medicare - surgeon & 424.06 & $1,279.62$ \\
\hline Total & $18,17 \mid .18$ & $27,078.81$ \\
\hline \multicolumn{3}{|l|}{ Implantation of stimulator } \\
\hline Medicare - conservative therapy & 892.49 & $1,621.35$ \\
\hline Medicare - DRG 029 & $20,946.67$ & $34,262.00$ \\
\hline Medicare - surgeon & 142.00 & 492.00 \\
\hline Total & $21,886.91$ & $36,375.35$ \\
\hline \multicolumn{3}{|l|}{ Ancillary costs } \\
\hline MRI CPT-7322I & 203.84 & 791.94 \\
\hline CT scan CPT-772I7 & 146.26 & 140.33 \\
\hline Epidural steroid injection CPT-623II & 132.34 & 290.66 \\
\hline Physical therapy CPT-97530 & 122.85 & 93.04 \\
\hline Unscheduled office visit CPT-99215 & 192.96 & 305.38 \\
\hline Conservative therapy total & 892.49 & $1,621.35$ \\
\hline
\end{tabular}

Abbreviations: APC, ambulatory payment classification; CPT, current procedural terminology; CT, computed tomography; DRG, diagnosis-related group; MRI, magnetic resonance imaging; PT, physical therapy.

complications occurred in $3.3 \%$ of the ACD patients and $8.6 \%$ of the control patients ( $P=0.01$; Table 2$)$, and the rate of reoperations for recurrent herniation was significantly lower among ACD patients $(0.7 \%$ vs $4.0 \%, P=0.02)$. Within a 90-day bundled payment period, the average cost to treat 
90-day per-patient costs
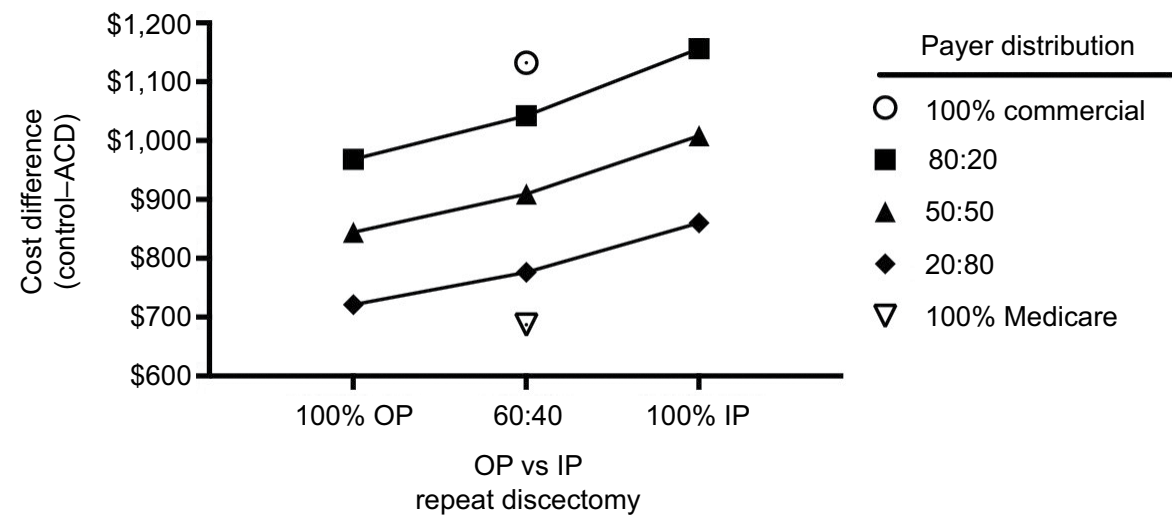

Figure I Sensitivity analysis of 90-day per-patient cost differences.

Notes: Sensitivity analysis of the differences in 90-day costs between control and ACD-treated patients was conducted by varying the distribution of Commercial payers vs Medicare and the ratio of repeat discectomies performed in an OP vs IP setting. Costs include the index discectomy plus additional direct health care costs during the 90 -day follow-up period, but the ACD device cost was not included in this analysis. All costs are represented in US dollars (\$).

Abbreviations: ACD, annular closure device; IP, inpatient; OP, outpatient.

Table 2 Summary of 90-day clinical outcomes affecting direct costs

\begin{tabular}{|l|l|l|l|}
\hline & ACD & Control & P-value \\
\hline Reherniation (\%) & 2.2 & 6.8 & 0.01 \\
Post-op complications (\%) & 3.3 & 8.6 & 0.01 \\
Revision surgery (\%) & 1.9 & 5.4 & 0.03 \\
\hline
\end{tabular}

Note: aPost-op complications included wound dehiscence, infection, epidural hematoma, or device failure.

Abbreviations: ACD, annular closure device; post-op, post-operative.

Table 3 Summary of 90-day direct cost estimates under varying payer distributions

\begin{tabular}{|l|l|l|l|l|}
\hline $\begin{array}{l}\text { Repeat } \\
\text { discectomy: }\end{array}$ & $\begin{array}{l}\text { Payer } \\
\text { 60\% }\end{array}$ & $\begin{array}{l}|c| \\
\text { distribution (\%) } \\
\text { Outpatient, }\end{array}$ & $\begin{array}{l}\text { Estimated direct health care } \\
\text { costs (\$USD) }\end{array}$ \\
\cline { 2 - 5 } $\begin{array}{l}\text { Medicare } \\
\text { 40\% }\end{array}$ & ACD & Control & Difference \\
\cline { 2 - 5 } inpatient & $100: 0$ & 11,123 & 12,255 & 1,132 \\
& $80: 20$ & 10,257 & 11,299 & 1,042 \\
& $50: 50$ & 8,956 & 9,865 & 909 \\
& $20: 80$ & 7,654 & 8,430 & 776 \\
& $0: 100$ & 6,787 & 7,474 & 687 \\
\hline
\end{tabular}

Note: ${ }^{a}$ Costs include index discectomy plus additional direct health care costs during 90-day follow-up; the ACD device cost was not included in this analysis. Abbreviation: $A C D$, annular closure device.

an ACD patient (not including device cost) was $\$ 10,257$ compared to $\$ 11,299$ per control patient for a 80:20 distribution of Commercial:Medicare coverage (Table 3 ). Therefore, under this payer distribution, using the ACD in this high-risk population would reduce direct health care costs by an average of $\$ 1,042$ per patient, primarily due to a reduction in the incidence of reoperation due to reherniation in the ACD group. When considering alternative scenarios of $100 \%$ Commercial or $100 \%$ Medicare populations, the average cost difference was $\$ 1,132$ or $\$ 687$, respectively (Table 3). These costs were based on an assumption of repeat discectomies performed on a $60 \%$ OP and $40 \%$ IP basis. In the case of an 80:20 Commercial:Medicare population, adjusting this assumption to a $100 \%$ OP setting for repeat discectomies changed the 90-day cost estimates to $\$ 10,162$ for ACD patients and $\$ 11,130$ for control patients $(\Delta=\$ 968)$. In a $100 \%$ IP setting, these estimates were $\$ 10,397$ and $\$ 11,553$ $(\Delta=\$ 1,156$; Figure 1).

\section{Discussion}

Discectomy patients with large annular defects are easily identifiable at the time of surgery and are known to be at high risk for recurrent herniation. Therefore, operative strategies that reduce reherniation rates in these patients, such as the ACD evaluated in this study, are highly advantageous from both a patient care perspective and an economic perspective. To better define the impact value of the ACD under a 90-day bundled payment system, this study estimated the US health care costs that would be associated with treating high-risk discectomy patients from the RCT (with or without ACD) from index surgery through 90-day follow-up.

For any given episode-of-care, costs and reimbursement can vary widely depending on the surgeon, hospital, patient insurance coverage, and IP vs OP care. ${ }^{8,19,20}$ For discectomy or decompression procedures, Jain et $\mathrm{al}^{8}$ calculated average 90-day bundle costs of $\$ 11,091$ for patients with Commercial 
insurance and $\$ 6,239$ for patients with Medicare, who experienced reoperation rates of $2.7 \%$ and $1.8 \%$, respectively. In this analysis of US health care costs, the average 90-day bundle costs were $\$ 12,255$ for Commercial coverage and $\$ 7,474$ for Medicare in the control group, which had a reoperation rate of 5.4\%. In contrast, the ACD group had a significantly lower reoperation rate of $1.9 \%$ and lower 90 -day cost estimates of $\$ 11,123$ and $\$ 6,787$ for Commercial and Medicare reimbursement, respectively. The revision rate for the control group of high-risk, large annular defect patients in the RCT was at least twice as high as the revision rate for the general discectomy population described by Jain et al. ${ }^{8}$ This is consistent with a previous meta-analysis that reported that large annular defect patients have a risk of index-level reoperation 2.3 times greater than patients with smaller annular defects. ${ }^{9}$ The cost estimates and reoperation rates reported here for the ACD group are similar to the measurements of Jain et al in the general lumbar discectomy population. ${ }^{8}$ This demonstrates that the ACD was able to reduce reoperation rates and 90-day post-operative costs in this high-risk population back to the average level of the general discectomy population. Taken together, it is clear that proactive identification and management of these high-risk patients could directly mitigate a substantial cost generator (reherniation) in this population. ${ }^{21}$

One limitation of this study is that the cost for the ACD was not included in order to directly compare cost differences during the 90-day follow-up period. This method provides insights into the differences in post-operative complications, reoperations, and associated costs. The device cost could be directly compared alongside the potential cost reduction observed in this analysis; however, those costs should also be considered in light of the patient's reduced risk for experiencing a recurrent herniation and/or reoperation. Ament et $\mathrm{al}^{22}$ modeled the cost of this device to be $\$ 3,000$, which would result in a net average cost of $\$ 1,958$ after the savings calculated for the 90 -day post-operative period $(\$ 1,042)$. Considering that the rate of reoperation for recurrent herniation was reduced nearly sixfold during the first 90 days $(0.7 \%$ in the ACD group vs $4.0 \%$ in the control group), the additional cost for the device may be justified to help prevent further patient morbidity and socioeconomic costs, which were not modeled in this study.

Another limitation to consider is that most of the study was open-label, so it is possible that trial participants (physicians and patients) may behave differently if the ACD technology was used. Finally, US direct cost data were estimated based on a fee-for-service database because limited data are currently available for bundled payment schemes.

\section{Conclusion}

High-risk discectomy patients require additional resources and incur a greater cost to the health care system due to more frequent reherniations and reoperations. Technologies that sufficiently mitigate risks within these target populations, such as the ACD in this study, help diminish these costs. The frequency of reoperations due to recurrent herniation was reduced nearly sixfold $(0.7 \%$ vs $4.0 \%, P=0.02)$ in patients treated with an ACD, which translated to an estimated direct cost savings up to nearly $\$ 1,200$ per patient during the 90-day post-operative period. Treatment strategies such as this ACD will be important to consider as reimbursement practices continue to evolve and place greater emphasis on the quality of care.

\section{Acknowledgment}

The authors would like to acknowledge Telos Partners, LLC for their technical editing contributions.

\section{Disclosure}

JDA received consulting fees from Intrinsic Therapeutics related to the cost calculations for this study. CT, JDA, and MJM have received educational consulting fees unrelated to this work from Intrinsic Therapeutics. CT's institution received study support for conducting the RCT from Intrinsic Therapeutics. All other authors are free from any potential conflicts of interest related to this work.

\section{References}

1. Martin BI, Deyo RA, Mirza SK, et al. Expenditures and health status among adults with back and neck problems. JAMA. 2008;299(6): 656-664.

2. Hackbarth G, Reischauer R, Mutti A. Collective accountability for medical care - toward bundled Medicare payments. $N$ Engl J Med. 2008;359(1):3-5.

3. Ellimoottil C, Ryan AM, Hou H, Dupree JM, Hallstrom B, Miller DC. Implications of the definition of an episode of care used in the comprehensive care for joint replacement model. JAMA Surg 2017;152(1):49-54.

4. Ugiliweneza B, Kong M, Nosova K, et al. Spinal surgery: variations in health care costs and implications for episode-based bundled payments Spine. 2014;39(15):1235-1242.

5. Lang SS, Chen HI, Koch MJ, et al. Development of an outpatient protocol for lumbar discectomy: our institutional experience. World Neurosurg. 2014;82(5):897-901.

6. Leven D, Passias PG, Errico TJ, et al. Risk factors for reoperation in patients treated surgically for intervertebral disc herniation: a subanalysis of eight-year sport data. J Bone Joint Surg Am. 2015;97(16): 1316-1325.

7. Martin BI, Mirza SK, Flum DR, et al. Repeat surgery after lumbar decompression for herniated disc: the quality implications of hospital and surgeon variation. Spine J. 2012;12(2):89-97.

8. Jain N, Virk SS, Phillips FM, Yu E, Khan SN. A 90-day bundled payment for primary single-level lumbar discectomy/decompression: what does "Big Data” Say? Clin Spine Surg. 2018;31(3):120-126. 
9. Miller LE, Mcgirt MJ, Garfin SR, Bono CM. Association of annular defect width after lumbar discectomy with risk of symptom recurrence and reoperation: systematic review and meta-analysis of comparative studies. Spine. 2018;43(5):E308-E315.

10. Hahn BS, Ji GY, Moon B, et al. Use of annular closure device (Barricaid $($ ) for preventing lumbar disc Reherniation: one-year results of three cases. Korean J Neurotrauma. 2014;10(2):119-122.

11. Klassen PD, Bernstein DT, Köhler HP, et al. Bone-anchored annular closure following lumbar discectomy reduces risk of complications and reoperations within 90 days of discharge. J Pain Res. 2017;10:2047-2055.

12. Parker SL, Grahovac G, Vukas D, et al. Effect of an annular closure device (Barricaid) on Same-Level recurrent disk herniation and disk height loss after primary lumbar discectomy: two-year results of a multicenter prospective cohort study. Clin Spine Surg. 2016;29(10):454-460.

13. Thomé C, Klassen PD, Bouma GJ, et al. Annular closure in lumbar microdiscectomy for prevention of reherniation: a randomized clinical trial. Spine J. 2018;18(12):2278-2287.

14. Klassen PD, Hes R, Bouma GJ, et al. A multicenter, prospective, randomized study protocol to demonstrate the superiority of a bone-anchored prosthesis for anular closure used in conjunction with limited discectomy to limited discectomy alone for primary lumbar disc herniation. Int J Clin Trials. 2016;3(3):120.

15. International Organization for Standardization. 2011. Clinical investigation of medical devices for human subjects - Good Clinical Practice (ISO 14155:2011). Available from: https://www.iso.org/standard/45557. html. Accessed September 6, 2017.
16. Marketscan. Commercial Claims and Encounters and Medicare Supplemental Databases; 2011. Available from: https://www.ibm.com/us-en/ marketplace/micromedex-red-book. Accessed September 6, 2017.

17. Pugely AJ, Martin CT, Gao Y, Mendoza-Lattes S. Causes and risk factors for 30-day unplanned readmissions after lumbar spine surgery. Spine. 2014;39(9):761-768.

18. Medical Consumer Price Index. Bureau of Labor Statistics. Washington, DC: United States Department of Labor; 2016. Available from: https:// www.bls.gov/cpi/data.htm. Accessed September 1, 2017.

19. Fry DE, Nedza SM, Pine M, Reband AM, Huang CJ, Pine G. Inpatient and 90-day post-discharge outcomes in elective Medicare spine fusion surgery. Spine J. 2017;17(11):1641-1649.

20. Sielatycki JA, Chotai S, Wick J, Sivaganesan A, Devin CJ. Intersurgeon cost variability in anterior cervical discectomy and fusion. Spine. 2018;43(16):1125-1132.

21. Mccarthy IM, Hostin RA, Ames CP, et al. Total hospital costs of surgical treatment for adult spinal deformity: an extended follow-up study. Spine J. 2014;14(10):2326-2333.

22. Ament J, Thaci B, Yang Z, et al. Cost-effectiveness of a bone-anchored annular closure device versus conventional lumbar discectomy in treating lumbar disc herniations. Spine. 2019;44(1):5-16. 


\section{Supplementary materials}

\section{Local ethics committees that gave approval for the randomized controlled trial:}

- Ethikkommission: Medizinische Universität Graz

- Ethikkommission der Medizinischen Universität Innsbruck

- ZiekenhuisNetwerk Antwerpen (ZNA/OCMW Antwerpen)

- O.L.Vrouwziekenhuis Aalst Ethisch Comite

- ZNA/OCMW Antwerpen

- Commissie voor Medische Ethiek, A.Z. Nikolaas

- Comité de Protection des Personnes (CPP)

- MHH (Hannover Medical School)
- BLÄK (Ethics Committee of the Bavarian Regional Medical Association)

- Charité Ethikkommission

- Medizinische Fakultät Der Christian-Albrechts-Universität Zu Kiel

- Med. Ethik-Kommission II

- Heinrich Heine Universität Düsseldorf Ethikkommission der Medizinischen Fakultät

- Ethik-Kommission Der Ärztekammer Hamburg

- Ethikkommission an der Medizinischen Fakultät der Universität Rostock

- Ethik-Kommission der Medizinischen Fakultät der RUB

- St. Lucas Andreas Ziekenhuis

- Isala Klinieken

- METC Zuidwest Holland

- Kanton Aargau,Kantonale Ethikkommission
ClinicoEconomics and Outcomes Research

\section{Publish your work in this journal}

ClinicoEconomics and Outcomes Research is an international, peerreviewed open-access journal focusing on health technology assessment, pharmacoeconomics and outcomes research in the areas of diagnosis, medical devices, and clinical, surgical and pharmacological intervention. The economic impact of health policy and health systems

\section{Dovepress}

organization also constitute important areas of coverage. The manuscript management system is completely online and includes a very quick and fair peer-review system, which is all easy to use. Visit http://www.dovepress.com/testimonials.php to read real quotes from published authors.

Submit your manuscript here: https://www.dovepress.com/clinicoeconomics-and-outcomes-research-journal 